\title{
'DRAGGING HER DIRT ALL OVER THE NET': PresenCe, INTIMACY, MATERIALITy V1.0
}

\author{
Transforming Cultures eJ ournal, \\ Vol. 2 No 2, December 2007 \\ http:// epress.lib.uts.edu.au/journals/TfC
}

\section{Esther Milne $^{1}$}

\begin{abstract}
How is intimacy produced within digitally enabled communication platforms such as the mailing list? How do geographically dispersed subjects represent and 'make present' their identity? This paper addresses such questions through a case study of the email discussion group, Cybermind. Providing an evocative example of the power and affective relations across mailing list culture, the case study demonstrates that, contrary to the popular critical imagination, the linguistic and rhetorical behaviours of the online self function in a manner that is relatively predictable and therefore fairly stable. Thus the paper challenges the 1990s dream of the online, radically decentred subject. This does not overlook the fact that identity is always a performance and the product of highly mediated cultural, material and institutional forces. However, the complex interplay between technology, fantasy and materiality in the shaping of identity has not been fully explored. Crucial to the production of identity are the symbolic and technological relations of presence. Authors assume that the material signifiers of writing can be deployed to express, to make present, the particular version of subjectivity they wish to convey. Moreover, even the representations of multiple and playful selves are, in fact, quite carefully governed by their authors. The paper concludes with a discussion of the extent to which the socio-technical architecture of the mailing list is conditioned by fantasies of presence and economies of affect.
\end{abstract}

[key words: presence, email, intimacy]

\section{Introduction}

In this medium ... there is absolutely no relevance to our physical selves. There is no problem with being any color, any gender, any weight, any physical limitations/disabilities, any social level, any timezone. [Y] ou have a blank slate to draw on and project your true self (or the self you aspire to

\footnotetext{
${ }^{1}$ Esther Milne teaches in the Media and Communications Department at Swinburne University, Melbourne, Australia. She has subscribed to Cybermind since 1998 and is also a facilitator for the Australasian mailing list for critical internet research, Fibreculture.
} 
be). Unfortunately, many people tend to bring their baggage with them and then use it as a crutch. ${ }^{2}$

[I]n text-based, digital communication, conventional signals of gender, such as intonation and voice pitch, facial features, body image, nonverbal cues, dress, and demeanour, are absent. Thus, the idea of gender-free communication becomes conceivable for the first time. ${ }^{3}$

People in virtual communities do just about everything people do in real life, but we leave our bodies behind. ${ }^{4}$

Questions surrounding the construction of identity have been central to research about digitally enabled communication systems. The fact that interlocutors do not, in general, share physical location and therefore are not physically present to each other has led many commentators to imagine the emancipation possible when conventional indicators of gender, race and class appear invisible. In these narratives of freedom, the subject is fragmented, multiple, and self-determining. These qualities invest the subject with the power to resist positioning within structures of hegemony. As Byron Burkhalter writes of Usenet communication:

In face-to-face interaction an individual's physical characteristics, from skin colour to vocal patterns, help convey racial identity. Lacking such physical cues on computer networks, one might predict that discrimination on the basis of race, age, gender, sexuality, class, status, and group membership would disappear ${ }^{5}$.

\footnotetext{
${ }^{2}$ Joe, “Re: WEB SITE INTRODUCTION PAGE," Cybermind online posting, 17 September 2002. The Cybermind archives have moved through at least two servers each with quite different storage policies. During 2000, without warning AOL deleted two years of list email. Despite requests from Cybermind members, the missing data were not retrieved. However, the author holds copies of all emails cited. Cybermind citations are abbreviated in the following manner:

Cybermind A Postings between 17 March 1995 and 23 January 2000 are held at $<$ http://www.anu.edu.au/mail-archives/cybermind/>. The author holds copies of all cited postings.

Cybermind B $\quad$ Postings to Cybermind Discussion Group between 1 January 2000 and 31 December 2002 are no longer accessible electronically. The author holds copies of all cited postings.
}

The current Cybermind archives are held at:

$<$ http://listserv.aol.com/archives/cybermind.html>. The names of all mailing list participants have been changed unless otherwise directed by those participants.

${ }^{3}$ Brenda Danet, “Text as Mask: Gender, Play, and Performance on the Internet,” in Steven Jones ed. CyberSociety 2.0: Revisiting Computer-Mediated Communication and Community, Thousand Oaks, Sage, 1998: 136.

${ }^{4}$ Howard Rheingold, The Virtual Community: Surfing the Internet, London, Minerva, 1994: 3.

${ }^{5}$ Byron Burkhalter, "Reading Race Online: Discovering Racial Identities in Usenet Discussions," in Marc A. Smith and Peter Kollock (eds) Communities in Cyberspace, New York, Routledge, 1994: 63. 
The absence of such indicators, it is argued, allows online subjectivity to be playful, performative, flexible and decentred ${ }^{6}$. According to this view, there is no essential "rational, autonomous, centred and stable" ${ }^{7}$ core to identity. Other writers, also arguing for the egalitarian possibilities of computer mediated communication (CMC), claim that computer-media strips bodies clean of the marks of culture, revealing the "real" self. As Joe notes in the opening quotations, race and gender are limitations that obscure one's "true" self. Ironically, the "mutability of identity on-line"8 also opens the possibility of "faking” one's identity, for deception, duplicity and betrayal ${ }^{9}$.

A substantial body of research has questioned the technological production of a decontexualised, incorporeal, genderless, raceless and ageless subject. Burkhalter, for example, argues that race is just as "relevant" in online interaction as it is in face-to-face communication; indeed, "racial stereotypes may be more influential and resilient” on Usenet $^{10}$. Marc Smith and Peter Kollock echo these views: "traditional status hierarchies and inequalities are reproduced in online interaction and perhaps are even magnified"11. In contrast to writers who celebrate the decentred, fragmented selves of CMC, Beth Kolko and Elizabeth Reid argue that "fragmented projections of the self can become fixed and invariable, and can preclude flexible social interaction”"12. A number of feminist writers have found that far from avoiding gender stereotypes, the discursive practices of CMC exaggerate them. Rather than being "erased in the virtual world,"

\footnotetext{
${ }^{6}$ Elizabeth Reid, "Virtual Worlds: Culture and Imagination,” in Steven Jones (ed.) Cybersociety: Computer-Mediated Communication and Community, London, Sage, 1995: 164-83; Shannon McRae, "Flesh Made Word: Sex, Text and the Virtual Body" in David Porter (ed.) Internet Culture, New York, Routledge, 1997: 73-86; Allucquére Rosanne (Sandy) Stone, The War of Desire and Technology at the Close of the Mechanical Age, Cambridge, Mass, MIT Press 1995; Sherry Turkle Life on the Screen: Identity in the Age of the Internet, New York, Simon \& Schuster, 1995; Mark Poster, The Mode of Information: Poststructuralism and Social Context, Cambridge, Polity, 1990; Danet (1998).

${ }^{7}$ Mark Poster, "Postmodern Virtualities,” in Mike Featherstone and Roger Burrows (ed.) Cyberspace, Cyberbodies, Cyberpunk: Cultures of Technological Embodiment, London, Sage, 1995: 80.

${ }^{8}$ Steven Jones, introduction to Steven Jones (ed.) CyberSociety 2.0 Revisiting Computer-Mediated Communication and Community, Thousand Oaks, Sage, 1998: xv.

${ }^{9}$ Julian Dibbell, “A Rape in Cyberspace: How an Evil Clown, a Haitian Trikster Spirit, Two Wizards, and a Cast of Dozens Turned a Database into a Society,” in Mark Stefik (ed.) Internet Dreams: Archetypes, Myths, and Metaphors Cambridge, MIT Press, 1996: 293-315; Allucquére Rosanne (Sandy) Stone, "Will the Real Body Please Stand Up?: Boundary Stories about Virtual Cultures,” in Michael Benedikt (ed.) Cyberspace: First Steps, Cambridge, Mass, MIT Press, 1991: 81-118.

${ }^{10}$ Burkhalter (1999: 74).

${ }^{11}$ Peter Kollock and Marc A. Smith, “Communities in Cyberspace,” in Smith and Kollock, (1994: 9).

${ }^{12}$ Beth Kolko and Elizabeth Reid, "Dissolution and Fragmentation: Problems in On-Line Communities," in Steven G. Jones (ed.) CyberSociety 2.0 Revisiting Computer-Mediated Communication and Community, Thousand Oaks, Sage, 1998: 213.
} 
Kira Hall argues that gender is intensified: “in the absence of the physical, network users exaggerate societal notions of femininity and masculinity in an attempt to gender themselves” ${ }^{13}$. A similar conclusion is reached by Susan Herring in her study of power and gender on the internet. Herring notes the prediction that gender differences would be rendered "invisible or irrelevant" on the Internet have not been realised. Instead, “traditional gender differences” are evident across a multiplicity of internet platforms in relation to "discourse style and patterns of disparity and harassment, and on the Web, in images, content, and patterns of use" ${ }^{14}$. Interestingly, Herring discovered that this research did not find straightforward correlations in the linguistic patterns of singleauthored blogs. ${ }^{15}$ Specifically, her study, concerning gender and genre differences in blog presentation styles, found that the gender of the blog's author could not be predicted by linguistic features as easily as gender could be predicted across other forms of textual online communication ${ }^{16}$. One possible explanation for this variance could lie with the different levels of interactivity afforded by mailing lists and blogs. In contrast to blogs, mailing lists seem to demand a higher level of interactivity and exchange between conversational partners. Perhaps this ensures blog writers are less likely to feel pressure to conform to a particular generic and gendered pattern of communication. However, as Melissa Gregg has argued, 'blogging’s gender wars’ are a complex site of contestation, requiring a “multifaceted approach that doesn't rely too heavily on one interpretive lens" ${ }^{, 17}$.

13 Kira Hall, “Cyberfeminism," in Susan C. Herring (ed.) Computer-Mediated Communication: Linguistic, Social and Cross-Cultural Perspectives, Amsterdam: Benjamins, 1996: 148 \& 167. See also C. Bassett, "Virtually Gendered: Life in an Online World," in Ken Gelder and Sarah Thornton (eds) The Subcultures Reader, London, Routledge, 1997: 537-50; Claudia Springer, Electronic Eros: Bodies and Desire in the Postindustrial Age, Austin, University of Texas Press, 1996.

${ }^{14}$ Susan Herring, “Gender and power in on-line communication”, in J. Holmes and M. Meyerhoff (eds) The Handbook of Language and Gender, Oxford, Blackwell, 2003: 218.

${ }^{15}$ As many researchers note, blog culture does not represent a simple, homogenous socio-technological genre. See, for example, Adrian Miles, 'Media Rich versus Rich Media' paper given at Blogtalk Downunder conference May 19-22 2005, Sydney: <http://incsub.org/blogtalk/?page_id=76>; Rebecca Blood, (2000), "Weblogs: A History and Perspective", $<$ http://www.rebeccablood.net/essays/weblog_history.html>; and Axel Bruns and Joanne Jacobs Uses of Blogs, New York, Peter Lang, 2006.

${ }^{16}$ Susan Herring and John Paolillo, “Gender and genre variation in weblogs”, Journal of Sociolinguistics, 10(4), (forthcoming); a pre-publication version is available through The (We)blog Research on Genre Project (Brog) <http://www.blogninja.com/jslx.pdf>.

${ }^{17}$ Melissa Gregg, "Posting with Passion: Blogs and the Politics of Gender” in Axel Bruns and Joanne Jacobs (ed.) Uses of Blogs, New York, Peter Lang, 2006: 151. 
As a form of critical resistance, the rhetoric of choice has come under increasing scrutiny since the late $1990 \mathrm{~s}^{18}$. Amronhini Sahay, for example, argues that cybercultural theory imagines the fragmented, multiple and self-determining cybersubject as "a mode of resistance to (cyber) capitalist social relations” ${ }^{\text {19 }}$. Yet, as Sahay demonstrates, this figure serves market ideology through its celebration of choice and emphasis on selfinvention. She coins the term “cybermaterialism” which describes a:

non transformative materialism that is deployed primarily as a device to avert attention away from the "working day"... and onto the "everyday" which is then theorised as a space of limitless self-invention. In a broad historical sense cybermaterialism, and cyberspace more generally, are explained as partaking in the larger celebratory effort following upon the collapse of eastern European socialism and the resurgence of free market ideology to post the notion that capitalism itself is "beyond" social transformation $^{20}$.

Specifically, in terms of the emergence of particular identity formulations, Sahay argues that the cybersubject who is forged out of poststructuralist tropes of desire, pleasure, indeterminacy and excess offers very little material resistance to hegemonic social forces. Addressing poststructuralist critics such as Judith Butler, she asks:

[I]sn't this subject, as a figure of unchecked desire who deconstructs ideology by virtue of her excessive practices, specifically a bourgeois subject who finds herself unconstrained by the materiality of social practices and is thus merely an alibi for the autonomous and free agent of a triumphant free market capitalism that similarly imagines itself beyond any social consequences? ${ }^{21}$

Contemporary research also questions the strict dichotomy sometimes assumed to exist between "online” and "offline” identity. As Nancy Baym notes, "the reality seems to be that many, probably most, social users of CMC create online selves consistent with their off-line identities"22.

\footnotetext{
${ }^{18}$ See, for example, David Harvey A brief history of neoliberalism, New York, Oxford, University Press, 2005 and John Sanbonmatsu, The postmodern prince : critical theory, left strategy, and the making of a new political subject, New York, Monthly Review Press, 2003.

${ }^{19}$ Amrohini Sahay, “'Cybermaterialism' and the Invention of the Cybercultural Everyday,” New Literary History 28(3) 1997: 544.

${ }^{20}$ Ibid

${ }^{21}$ Ibid: 549.

${ }^{22}$ Nancy K. Baym, “The Emergence of On-Line Community,” in Jones 1998: 55. On re-evaluating the distinction between online and offline practice see Don Slater, "Social Relationships and Identity Online and Offline," in Leah Lievrouw and Sonia Livingstone (eds) Handbook of New Media: Social Shaping and Consequences of ICTs, London, Sage, 2002: 533-46; Barry Wellman and Caroline Haythornthwaite (eds), The Internet In Everyday Life (Oxford: Blackwell, 2002).
} 
This paper locates a critique of the flexible, fragmented and "decentred” subject within a case study of the email discussion group Cybermind. Through the examination of email exchanges the paper argues that, to a large degree, the linguistic behaviours and rhetorical gestures of the various selves produced through the list function in a manner that is relatively predictable and therefore fairly stable. This does not disavow the fact that identity is always a performance and the product of highly mediated cultural, material and institutional forces. However, the complex interplay between technology, fantasy and materiality in the shaping of identity has not been fully explored. The data was selected for this analysis because it demonstrates that the materiality of a distributed community can thwart the autonomy one may have over the presentation of identity.

Crucial to the production of identity is the socio-technological question of presence. As we shall see, whether these subjectivities are represented as, on the one hand, "singular," "rational and autonomous" or, on the other hand, "multiple," "fragmented" and "decentred," the assumption is that the self can be made present on Cybermind. The selves of Cybermind often conform to what has been called the "expressivist" paradigm $^{23}$ within which presence plays a crucial role ${ }^{24}$. Authors assume that the material signifiers of writing can be deployed to express, to make present, the particular version of subjectivity they wish to convey. Moreover, even the representations of multiple and playful selves are, in fact, quite carefully governed by their authors.

\footnotetext{
${ }^{23}$ See, for example, Johnnie Gratton, Expressivism: The Vicissitudes of a Theory in the Writing of Proust and Barthes, Oxford, Legenda, 2000; and Catherine Belsey, Critical Practice, London, Routledge, 2002.

${ }^{24}$ Presence is a major field of enquiry for researchers of digitally mediated, networked culture. See, for example, Richard Coyne, Technoromanticism: Digital Narrative, Holism, and the Romance of the Real, Cambridge, Mass, MIT Press, 2001; Jeffrey Sconce, Haunted Media: Electronic Presence from Telegraphy to Television, Durham, Duke University Press, 2002; Vivian Sobchack, "The Scene of the Screen: Envisioning Cinematic and Electronic 'Presence'” in Hans Ulrich Gumbrecht and K. Ludwig Pfeiffer (eds) Materialities of Communication, Stanford University Press, 1994: 83-106; William Mitchell e-topia, Cambridge, Mass, MIT Press, 1999; Peter Senge, C Otto Scharmer, Joseph Jaworski and Betty Sue Flowers, Presence - Exploring Profound Change in People, Organisations and Society, London: Nicholas Brealey Publishing, 2005; and Peter Glotz, Stefan Bertsch and Chris Locke (eds.), Thumb Culture: The Meaning of Mobile Phones for Society, Bielefeld, transcript Verlag, 2005. For an historical approach to technological presence see Milne, "Magic bits of paste-board': texting in the nineteenth century”, $M / C$ - A Journal of Media and Culture, 6.6 (2004) <http://journal.mediaculture.org.au/0401/02-milne.php>. For philosophical treatments of the term presence see Hans Ulrich Gumbrecht, Production of Presence: What Meaning Cannot Convey, Stanford University Press, 2004; and Jacques Derrida Of Grammatology, Baltimore, Johns Hopkins University Press, 1976.
} 
Having briefly surveyed some of the literature regarding the production of online subjectivity, the paper now explores the role of presence in the construction of gender and the performance of identity by analysing the email texts exchanged between two members of Cybermind. It begins by providing a brief introduction to these members, Alan Sondheim and Karen Crawford, outlining their roles within the list and their related online practices, before proceeding to an analysis of their exchanges ${ }^{25}$. These texts provide a compelling case study of the power and affective relations enabled by mailing list culture ${ }^{26}$. The paper concludes with a discussion of the extent to which the socio-technical architecture of the mailing list is conditioned by fantasies of presence and economies of affect.

\section{Alan Sondheim}

Sondheim is a New York writer, theorist and artist. He co-founded the email discussion lists, Cybermind and Wryting; lectures on cyberculture theory; regularly exhibits video and web installations and has published widely in both print and electronic forms. In 1999 he was the "virtual writer in residence" at the hypertext collective "trAce" based at Nottingham University in the UK. Sondheim's visibility as the moderator of Cybermind, his personal reactions to that job and his sense of commitment to the group is a defining feature of the list. It is rare for moderators of other mailing lists to achieve the same level of prominence or be treated with the same degree of deference. For example, Gilbert Rodman, the moderator of the discussion list Cultstud ("A listserve devoted to Cultural Studies”) ${ }^{27}$, occasionally reminds members of the correct procedures for posting messages and these posts often include complaints about the burden of administration. Nevertheless, they don't elicit the messages of reassurance and support as does Sondheim's labour: "BRAVO Mr. Sondheim. You work hard to keep this list running"28, "IMHO Alan Sondheim is one of the most interesting/brilliant/profound 'writers' I have had the good fortune to encounter"29. It is

\footnotetext{
${ }^{25}$ Biographical information for Sondheim and Crawford is gathered from a number of online sources in addition to the mailing list, Cybermind.

${ }^{26}$ For comprehensive historical case studies and critiques of mailing list culture see Geert Lovink, Dark Fiber: Tracking Critical Internet Culture (Cambridge, Mass: MIT Press, 2002).

$27<$ http://www.cas.usf.edu/communication/rodman/cultstud/index.html>

${ }^{28}$ sweetdreams, “Re: Newbies are worthless. Let’s all the oldbies commit public”, online posting, 2 June 1996, Cybermind A.

${ }^{29}$ Gregory, “Re: Radio,” online posting, 24 August 1999, Cybermind A. “IMHO” stands for the phrase "in my humble opinion”.
} 
difficult to overstate Sondheim's historical significance for and continuing influence on Cybermind. His discursive practices function as key strategies for creating a sense of intimacy within the list since being able to appreciate his work and understanding its historical specificity can confer upon a list member a degree of techno-cultural capital. The opportunity to display this authority arises when Sondheim's writing becomes the subject of a particular thread. Indeed, Sondheim's “ficto-theoretical” pieces appear so frequently on Cybermind that his work is likely to be encountered in the first days after a new member has joined. These texts are often so dense that, unaware that they are out of step with the group, the new member is likely to be openly critical of them. Soon after joining Cybermind, for example, Linda defined one of Sondheim's texts as "babble":

Though Mr. Sondheim presents evidence of sufficiently credible intelligence to suggest these strange, very strange, mutterings might be caused by more mundane influences. Perhaps a lack of sleep, or even strong drink ... I'm confident, though new to this list, that Mr. Sondheim is not such a fool as is suggested by his posted dribble ${ }^{30}$.

Linda's post generated about 20 replies: none agreed with her evaluation of Sondheim's writing; some implied that her reading skills were not up to the challenge of Sondheim's work, comparing it to authors such as "Wittgenstein - Gibson - Kruithof Hofstatter"31 . Linda was assured that perseverance would be rewarded: "stick around, you will certainly be surprised - and amazed”32, but she was also rebuked for failing to grasp the significance of Sondheim's work in relation to the operation of Cybermind. As Mario (a long-time Cybermind member and a frequent poster) commented:

There we go again. Invariably, when there is an influx of new members, someone comments about Alan's writings, often in derogatory terms. These people - I am certain - have not checked the archives and have not bothered to understand the rather unique spirit of this list and indeed of Alan's writings ${ }^{33}$.

Mario is right: the "unique spirit" of Cybermind is bound up with "Alan's writings". Moreover, as we shall see, there is a disjunction between Sondheim's representations of himself and those constructed by other list members. Rather than being simply negative, the consequent tension is a means of sustaining the effect of presence within

\footnotetext{
${ }^{30}$ Linda, “Re: Radio,” online posting, 24 August, 1999, Cybermind A.

${ }^{31}$ Roxanne, “Re: re Radio: are you listening?,” online posting, 24 August 1999, Cybermind A.

${ }^{32}$ Gregory, “Re: Radio,” online posting, 24 August 1999, Cybermind A.

33 Mario, “Re: Radio,” online posting, 25 August 1999, Cybermind A.
} 
Cybermind. The role played by the representation, interpretation, and reinterpretation of Sondheim's persona in the construction of a sense of presence are particularly noticeable in Sondheim's exchanges with Karen Crawford.

\section{Karen Crawford}

Crawford is an academic librarian, web designer and moderator of a number of networked discussion forums. As part of her online practice, Crawford has created a "web family," consisting of avatars she produces for use across various mailing lists forums, and other web-based activities. For example, under the pseudonym "Thadea," Crawford has participated in discussions on a site called "the labor of love" which, as the name suggests, is devoted to conception, pregnancy and childcare. Thadea, she explains,

has a husband, two small children, a gay brother-in-law who is the sweetest thing on earth, a niece who is living with the family, and an aunt who also does web design. The niece is applying to colleges and the oldest daughter has started full time kindergarten ${ }^{34}$.

Crawford has created a website devoted to Thadea and her family, carrying brief biographies of her children together with their "photographs". These images are unsettling in their odd combination of graphic styles and technologies. "Caltha's" image, for example, depicts a child whose body and head seem to be "cut and pasted" from two different sources. The child's head is disproportionately larger than its body. Moreover, her head is taken from a photographic source and "pasted" onto an illustration of a body which appears to be generated by a computer software program. Beneath the images, “Thadea” adds an apology:

The photos on this page did not scan well. Jacob, my husband, scanned them and then to improve them, I retouched them in PaintShop Pro. I fear I may have done more harm than good. Caltha's picture was taken when we went back east last winter to visit our parents... I apologise for the poor photo quality. I will try to find some better pictures and scan them myself ${ }^{35}$.

I shall argue that the creation of these fictional characters is central to the self presented by Crawford on Cybermind, and that these creations play a significant role in her interactions with Sondheim.

\footnotetext{
${ }^{34}$ Karen Crawford, “Why I like fraud,” online posting, 20 September 2002, NetDynam/Network Group Dynamics Mailing List <http://listserv.icors.org/archives/netdynam.html>

${ }^{35}$ Crawford, "A Page About My Daughters",

<http://web.archive.org/web/20020601172522/> <http://liquid2k.com/thadea/daughter.html>
} 
In addition to web-based discussion groups and email lists, Crawford's online activities include "site fighting," a web-based competition in which participants vote on the skill and design of each other's websites. A participant also solicits and "trades" votes, encouraging others to visit his/her website. On Cybermind, Crawford has regularly circulated publicity material for the competition, often written in an arcane and specialist language:

I did fight again ... as a Madd Hatter in April. It was another four week campaign and in the War Zone Jenna Denstad and I were up against MissCRafts (Cynical Cyndee) who had renamed a championship page that should have been retired. I had studied the fights a lot as a profoundly disaffected fighter and was glad I had such a bastard to be up against ${ }^{36}$.

Posts such as these are often difficult to decipher because Crawford refers indiscriminately, and without adequate explanation, to characters displayed on websites involved in the competition, the actual designers of these websites, and her own cast of fictional characters. Members of Cybermind by and large have not been willing to spend time understanding and interpreting her "site fight” posts and, indeed, often become hostile about their frequency, volume and strange content:

[C]an we skip to the part where they all climb in a chariot and rise up in the air for the big sky battle with the big Hindu god, only He never shows up, and the chariot full of Site Fighters is forced to land in a wheat field somewhere east of someone's hopelessly impossible daydream, in which the Site Fighters are forced to tunnel underground with sharp sticks and begin... a new life for a Thousand Years as the Dreamweaving Mole People, slowly losing their sight, but gaining with each handful of shovelled moist earth a rare kind of wisdom usually reserved for those special, special...few. ${ }^{37}$

[Y]ou are not giving us any respite on that extraordinarily tedious subject of site-fights... you do not generate any discourse which is relevant to CM... furthermore, the size of your post... was $21 \mathrm{k}$. In South Africa the telecommunication company charges us by the minute and whilst I will always look forward to witty prose regardless of size, I must regard $21 \mathrm{k}$ of useless, pedestrian prose as spam. Did you say you are going to post it “once a week"??? Excuse me, I've got to go and scream ${ }^{38}$.

Crawford usually appears untroubled by rejoinders such as these. Instead, they seem often to intensify the aggressive tone and combative behaviours that are hallmarks of

\footnotetext{
${ }^{36}$ Crawford, "In the dead of night," online posting, 21 August 1999, Cybermind A.

37 Tim, “Re: Poised for the attack....", online posting, 20 November 1999, Cybermind A (ellipses in original).

${ }^{38}$ Mario, “Re: Kosher salami,” online posting, 7 September 1999, Cybermind A.
} 
her online posts. Indeed, Crawford's aggressive tone and combative behaviours explain, in part, why she is frequently expelled from email discussion lists and the curious pleasure she seems sometimes to gain from these expulsions. As one list participant observes:

Karen, for the better part of six years you trot your pattern out that you replay over and over again. I'm stating the obvious: deep down you enjoy it.... [T]his behavior is consistent with a kind of edgy thrill seeking.... Your performance art fascinates me but you won't easily convince me that your own pattern isn't finally about the benefit of the titillating combat you always end up effecting ${ }^{39}$.

\section{Virtual Family: Avatars and Presence}

We now turn to a comprehensive study of the email exchanges between Crawford and Sondheim. Consisting of veiled threats, provisional apologies and theatrical exits, the correspondence between Crawford and Sondheim demonstrates how email is able to create a sense of presence and intimacy, how reading someone's emails can create the belief that one "knows" the person who writes. But these interactions also show the affective complexity of intimacy and presence, how an assumed intimacy may lead to rancour and hostility.

As mentioned, Sondheim's work is highly visible on Cybermind. It functions as a point of reference and authority for list members. Owing to its perceived obscurity, sophistication and inaccessibility, being able to understand and appreciate his work reflects well on the reader. Although appreciation may act as a type of currency on the list, appropriation is something altogether different as Crawford discovered. In late 1999, Sondheim began working on his “parable series” of texts. The parables explored issues of gender identity, power and virtuality through the use of his "avatars" or "virtual idols," characters and identities he assumes for aesthetic and theoretical $\operatorname{expression}^{40}$.

Sondheim regularly posts to the list in the name of one of these characters and indeed at times has them interacting with his own "identity”. In one post, for example, “Alan” and “Jennifer” engage in vibrator-assisted mutual masturbation:

\footnotetext{
${ }^{39}$ Sam, “Re: cumming again and again,” online posting, 14 August 2002, NetDynam.

${ }^{40}$ For an astute critique of virtuality, dematerialisation and power within the aesthetic field, see Anna Munster, Materializing New Media: Embodiment in Information Aesthetics, Hanover, Dartmouth College Press, 2006.
} 
Jennifer and Alan hear each other within the choir of the machine; they come as batteries expel the last embers of current. They are locked in each other arms; their nails have drawn blood. We are bruised membranes, molecular bubbles, they sing. They create a ballad of longing, drawing others to them... Jennifer thinks, perhaps I should say more, her body arched higher, her labia swollen, cauterised vibrator by her side. Alan thinks, there are apparitions, peerings, appearances, his chest and face damp with cum, castrated machine by his hole ${ }^{41}$.

Sondheim's parable series concern two identities called Nikuko and Doctor Leopold Konninger. Nikuko - “a beautiful Russian ballet dancer”42 - is one of Sondheim’s regular avatars and in his writing "she" is often used to explore female sexuality, female corporeality, technology, pornography and male identity. Nikuko texts, it has to be said, are not for the faint hearted. The language that Sondheim uses is shocking and, for some, offensive. In one post dedicated to Nikuko, for example, he describes his desire for "her" as "holes typing, holes slurring words, distracted holes, holes of speech naked holes ... doubled labia, quadrupled holes exposed ... labia held taut labia distended, thick scented...”43 Another text called "Full-Header and Half-Way Home” represents Sondheim sending an email "from" Nikuko to Cybermind. As part of this post he includes a long header that shows the various routers and servers through which the email has passed.

Hello, Oh you must see this! We have all wet our panties and sat on wires of alans@sva.edu and do you know we have lovely routers entering us through many new ways to speed text come to devour us it will be so fun to enter into wires, hello I am in your wires, oh oh oh I am your wires too just like, Whew! Last thing you might think of before you go to sleep tonighty-night ${ }^{44}$.

Given the volume of Sondheim's work and its somewhat controversial nature, it is not surprising that his texts often provoke quite passionate responses. Sometimes these responses are favourable and complimentary. Following a post from Sondheim where he expresses his misgivings about sending so many of his texts to the list, one Cybermind member writes:

\footnotetext{
${ }^{41}$ Alan Sondheim, "When It Comes," online posting, 23 May 2000, Cybermind B; also available: $<$ http://www.anu.edu.au/english/internet_txt/lk>.

${ }^{42}$ Sondheim, “DOCTOR LEOPOLD KONNINGER, ERROR MESSAGE," online posting, 4 November 1999, Cybermind A.

${ }^{43}$ Sondheim, "his answers, his wanting cunt, nikuko-awakened doctor, for azure," online posting, 31 July 1999, Cybermind A.

${ }^{44}$ Sondheim, "Playing with Sendmail," online posting, 22 May 2001, Cybermind B; also available: $<\mathrm{http}: / /$ www.anu.edu.au/english/internet_txt/lx>
} 
I have been knowing Nikuko, Jennifer, and Alan... and the rest.. since I joined this list, May 20, 1998... for two months, twenty six days, two hours and thirty two minutes Nikuko and Jennifer have grasped my mind. Alan Sondheim has fulfilled my brain with all those words, thousands unforgiving words which kept attacking every cell of my body. Yes your posts have taken too much of my time but then I can't live without them ${ }^{45}$.

But others, like Crawford, are not so full of praise. After a series of Sondheim's posts which explored "virtual idols," Japanese anime and gendered subjectivity (in quasi Joycean tones, he writes of Nikuko "Alway Luvly Swolen Beli Want for You to Look in Him”), Crawford admonished Sondheim quite firmly:

You ought to treat Nikuko better. You are her creator, her author, not her lover. Treat her right. Why do you drag her dirt all over the net for everyone to see? She was a good girl once until you dragged her through the mud and then disavowed it. ${ }^{46}$

Sondheim did not reply to Crawford at this time, nor did he a few months later when, again, she engaged with his work. Responding to one of his parable series in which Nikuko reads from The Diamond Sutra, Crawford “corrected” Sondheim:

Actually, Nikuko, didn't care one whit for the Diamond Sutra or philosophy. Nikuko got fat. After her hot shower, she dried off and put on a modest white blouse and a navy blue skirt that came down below her knees, driftwood colored pantyhose (the ones Sears always runs out of) and navy suede flats. She put a nice tortoise shell clip in her long brown hair and she told the good doctor to get in the shower because quite frankly, he stank and she wasn't going to be seen in public with a smelly old goat... During the week, Nikuko got a cat. She named him Alan. He was a six month old unaltered tom cat. He thought with what was below his tail. Because she got him from the pound she had to take him to be neutered. She felt this was no great loss because he tried to spray the walls a couple of times. He behaved better after being neutered. Sometimes when Dr. Konninger and Nikuko made love, Alan would join them on the water bed ${ }^{47}$.

This email is part of an engrossing battle with Sondheim over the meaning of his avatars. A fat, conservatively dressed Nikuko is contrary to the lithe form described by Sondheim as a "beautiful ballerina". Revealing the extent to which this battle is inflected by questions of gender, is the castration, in Crawford's narrative, of the cat named Alan. One could suggest that Sondheim and Crawford often resemble parents

\footnotetext{
${ }^{45}$ Lee, “Re: NOTE PLEASE!,” online posting, 16 August 1998, Cybermind A.

${ }^{46}$ Crawford, “Re: Diki (Kyoko Date, Date Kyoko, in Korea),” online posting, 31 August 1999, Cybermind A.

${ }^{47}$ Crawford, “Re: Parable,” online posting, 11 January 2000, Cybermind A.
} 
struggling with one another for control over their child/avatar. In this struggle each of them desires that the child/avatar be expressive of their own identities.

In Crawford's parody parable, "the good doctor" refers to the other important avatar created by Sondheim named Doctor Leopold Konninger. He is, as Sondheim puts it, "obsessed by the ballet dancer Nikuko"48. Konninger appears in a number of Sondheim's parables, invoking notions of Berlin cabaret:

Doctor Leopold Konninger says to Nikuko: We understand each other perfectly. Nikuko smiles. She has heard so much about the doctor. She says: You are mine for the evening, doctor. I will dance for you and no one else. The doctor wears thick pince-nez. He wears a black top-hat. He carries a cane. The doctor is silent. His eyes glitter. Nikuko says: But you must do one thing for me doctor... Nikuko says: You must remove your clothing. You must remove your eye-glasses. Who watches me is also watched. The doctor is silent. Nikuko continues: I will wear my tutu. It is embroidered with the flags of all the European nations. I will create a free and independent Europe. My entrechat speaks eloquently of free and sovereign states... The doctor is silent. He does not know what to think. Nikuko begins to dance. The doctor removes his pince-nez. The doctor puts down his cane ${ }^{49}$.

For some reason, Nikuko and Leopold Konninger captured Crawford's imagination. Perhaps because she had been piqued by Sondheim's refusal to engage with her remarks about his work, in late January 2000 it no longer seemed “enough” for her merely to post adaptations and interventions to the list. Instead, she designed a website devoted to Nikuko’s "new life”. She announced it with this post:

Hi all,

Alan, I know you have been very good at relating my parables, but I'm through writing them. I quit. I have just seen the light and had an awakening. I also built a brand new web page. It is small yet, but it is growing. Please have a look at it.

Nikuko Konninger

nikuko@melodymail.com ${ }^{50}$.

It is difficult to construct an adequate description of Crawford's web page and its very odd mix of aesthetic styles. The design's visual rhetoric and overall tone is perhaps best

\footnotetext{
48 Sondheim, “DOCTOR LEOPOLD KONNINGER, ERROR MESSAGE,” online posting, 4 November 1999, Cybermind A.

49 Sondheim, “Doctor Leopold Konninger,” online posting, 2 November 1999, Cybermind A.

${ }^{50}$ Crawford, “I have a web page. Please visit it,” online posting, 28 January 2000, Cybermind B.
} 
described as "faux naïve" or perhaps l'art brut". One could also categorise the illustrative thematic as “celestial”. The site is titled “Little Angel Nikuko's Humble Home on the Web" and is full of "cute” images of harpsichords, halos, birds, flowers and women with wings. It explains that Nikuko has suddenly changed her views and aesthetic practices, has married Leopold Konninger and is planning to have children. This rudimentary description, however, fails to do justice to the complexity, eccentricity and eclectic nature of Crawford's website. Some of the text from the site might provide a little more depth. The opening page reads:

Not long ago, I used to be a sophisticate in New York and Tokyo. I starred in avant-garde movies and wrote parables that no one could understand. People said they loved the stuff. Then one morning, I woke up and saw how bleak and grey my life was. That was when I learned that things get better, only if you let the sunshine in your heart. Right now I live with my husband Dr. Konninger, and he is the love of my life. I hope we'll be moving out of New York City soon to a nice little home in the country ${ }^{52}$.

Linked to this page is one called "Nikuko and Leo LOVE forever" which narrates how the two met and were married:

Back in my old life as an avant garde dancer, we were working together on a production. Leo would put on a top hat and a monacle and sit and stare. Sometimes a top hat and a monocle was all he would wear. I would wear a lavender tutu and dance ballet. We did this in an espresso bar for hours on end while the audience looked on. These were the people you read about, if you read that kind of stuff. They wore black and had white faces from not enough fresh air and sunshine. That was what we did, but hey we were making art! Then one morning I woke up. I was lying with Leo on the couch of the director's apartment. There was just no where else for us to sleep. We had been up all night talking Foucalt [sic] and Derrida and Lacan and other esoteric names that don't mean anything outside of academic circles and the real and the unreal and man and machine and how sex was at the center of it all, and I realized that what we were doing MEANT NOTHING! We just were playing to our own crowd of sophisticates and not helping anybody ${ }^{53}$.

Clearly, Crawford's piece is a critical appropriation of the performances and interactions that Sondheim had written for these two characters and had posted to Cybermind during the preceding year. In other sections on her site, "Nikuko" talks

\footnotetext{
${ }^{51}$ L'art brut ("raw art") coined by Jean Dubuffet to refer to works outside traditional definitions of art. Dubuffet collected art works by children, prisoners and the illiterate and used these "principles" in his own work: Robert Hughes, Shock of the New, London, Thames, 1991: 265-67.

52 Crawford, Little Angel Nikuko's Humble Home on the Web,

$<$ http://nakedmolerat.org.uk/peutje/nikuko.html>

${ }^{53}$ Ibid.
} 
about how she and Leo, after their wedding, "looked for somewhere to get a good dinner" since, as Nikuko explains, she "didn't have to squeeze into that tutu any more» ${ }^{54}$.

But perhaps the most noteworthy element of the site (and one to which Sondheim responds vociferously) is its pro-life rhetoric. According to the page called "Nikuko's Angel Garden,” it seems that Nikuko has adopted a family of angels, naming one of them after Sondheim. On this page, an image of a plaque-like greeting card is inscribed with the words, “Alan Julu (boy) Adopted 1/26/00" ("Julu” is the name of another of Sondheim's avatars). This “card” also carries text which accompanies an image of an angel and reads "Life a wonderful Choice” and "In Memory of the Unborn”. As Nikuko explains:

Collecting angels has been a great comfort to me. Just imagine cute little angels that always love, protect, and cherish you. Alan Julu was my first angel. He is named after my creator who abused me by dragging me through the mud. I pray for him and hope he someday changes his way. He did not care that a woman on his mailing list named a castrated tom cat after him but boy did he get angry when she named an unborn baby angel for him! ${ }^{55}$

In this description, the familial trope, mentioned above, is made problematic since Crawford casts Sondheim in the role of son to one of his own avatars. Of greater significance, however, is the fact that Crawford attempts to turn Sondheim into an avatar that supports militant pro-life rhetoric. This is an act that expresses both power and intimacy. Crawford exercises power over Sondheim by appearing to "reduce" his corporeal body to the status of representation. At the same time, however, this is a remarkably intimate, playful and flirtatious gesture, aimed, it seems, to provoke an emotional response from Sondheim.

What Sondheim interprets as Crawford's pro-life/anti abortion stance is illustrated on some of the other web pages that are part of her site. "Every Picture Tells A Story", for example, is written from the perspective of Nikuko’s niece, Zivia, who also has adopted an "unborn angel baby". This angel is called "Chiyo Koji” which, Zivia tells us, means “1,000 years”. Zivia explains that: “If I hadn’t been born because my mother didn’t want me or if my brothers and sisters hadn't been born, then that would have been a bad

\footnotetext{
${ }^{54}$ Ibid.

${ }^{55}$ Ibid.
} 
thing”. Although these kinds of comments could be described as only covertly "prolife”. Crawford links her page to a number of explicitly anti abortion sites: "Children are God's Greatest Gift. Help to save the children of this world born and unborn. You can Spiritualy Adopt an aborted child by stopping in at Di’s Angels”56.

It is not surprising that Crawford's announcement elicited a vigorous discussion on Cybermind. The first to respond was Sondheim:

Karen, on one hand I appreciate the page and the graphics, on the other I'm disgusted by the message. I don't think you understand the parables or what the work's about, which is of course your right, as it's your right to make the page, but to associate me with an anti-abortion position (unless you mean this as a joke) is ugly ${ }^{57}$.

Although Sondheim made an effort to be “open-minded” about Crawford's webpage - a short while later posting the message that "on the other hand, maybe you meant it as a caricature or satire, in which case my apology" him to leave the list: “I’m going nomail. I don’t see the humor in it. I don’t give a fuck whether it's cute etc. The politics in it are pernicious and I really don't want to deal with it any more" 59 . This prompted some list members to voice their disapproval of Crawford's attack on Sondheim's work:

I'd like to say that Alan deserves better than this. He's a fascinating thinker and creator. Full stop. "No ifs, ands or buts" as the saying used to go. What I'd like to know is why some people think that they can attack, mock or deride people like him? I don't get it. It's happened before when people take up and twist the work of others... Rather try to create your own work please. Leave Alan's work untouched ${ }^{60}$.

At this point, Crawford attempted to explain her intentions for the site, but this did little to allay the fear that Sondheim's work had been unfairly treated. According to Crawford, the web page was initially intended as a satire, but while she was working on it, she had a revelation. By the time she "adopted" the Alan Julu angel she "was no

\footnotetext{
${ }^{56}$ Dianne, “Di’s Angels”, <http://web.archive.org/web/20001001084504/http://geocities.com/Heartland/Valley/5955/index2.html> (spelling in original).

${ }^{57}$ Sondheim, “Re: I have a web page. Please visit it,” online posting, 29 January 2000, Cybermind B.

${ }^{58}$ Sondheim, “Karen’s page,” online posting, 29 January 2000, Cybermind B.

59 Sondheim, “nomail,” online posting, 29 January 2000, Cybermind B.

${ }^{60}$ Gregory, “Re: My web pagge [sic],” online posting, 29 January 2000, Cybermind B.
} 
longer at the point of parody. Something had happened"61. Crawford's change of heart demonstrates the significant role that presence plays in the construction of identity. That is, Crawford behaved as if her avatars existed as "real" children with their own rights and, moreover, that these children possessed the capacity to cause an emotional response in others. These children were so "expressive” they could cause Crawford to change her mind on ethical questions. As Crawford explained:

I really for a few minutes fell in love with my little angel baby as I got him ready for the page. I had seen how others took care of theirs, and they did a wretched job, leaving them on abandoned pages... I also felt inspired and made him a guardian for Alan Julu. I wanted a sibling for him and still do... If it wouldn't cost me the friendship of most of my sophisticated net buddies I would probably become pro-life ${ }^{62}$.

Perhaps because members weren't sure what to make of her explanation, list discussions continued to focus on the "wounding”63 of Sondheim by Crawford's satire, and before long Crawford sent the following public apology to Sondheim and the list:

Dear Alan,

I owe you this and I owe it publicly. Yes, the page was a joke and the adopt-a-fetus, as I called it at the time was one, WHEN I STARTED OUT. That was Thursday. By late Saturday afternoon, it was different. Something happened... I realized that it was time to put an end to the dissonance. I am prolife. Do not ask me where this leads politically. If you ask me a whole battery of political questions, I'll answer "I don't know" to most of them... Meanwhile, given the end result of the "joke" I would like to apologize to Alan. The next unborn angel I adopt will have a name given in sincerity, and probably adorn my first pro-life page. I'm sorry Alan. Please accept my apology ${ }^{64}$.

Sondheim did not publicly respond to this apology through the list; nevertheless, it refocussed the discussion on abortion and reproduction technologies.

Things, however, did not finish there. About a month later, Sondheim announced a video-art event starring Nikuko, Azure, Alan and the dancer Foofwa d'Imobilite (formerly of the well-known "Merce Cunningham Dance Company”):

Nikuko, the famous Russian ballet dancer, pirouettes for Doctor Leopold Konninger. These and other avatars from the Internet play out structures of language, body/movement, and desire. A sourceless hunger pervades

\footnotetext{
${ }^{61}$ Crawford, “Re: Karen’s page,” online posting, 29 January 2000, Cybermind B.

${ }^{62}$ Crawford, “Re: Karen’s page,” online posting, 29 January 2000, Cybermind B.

${ }^{63}$ Colin, “Re: Karen’s page,” online posting, 29 January 2000, Cybermind B.

${ }^{64}$ Crawford, “Apology to Alan,” online posting, 29 January 2000, Cybermind B.
} 
the work (which may be one work or many), created half in, half out, of cyberspace. We are all lost ghosts, discovering and abandoning language. Dance stutters or shudders among bodies. Pirouetting continues obsessively. All of us walk out of the tape, in one or another way, the beautiful styles of the day ${ }^{65}$.

And like the reappearance of a notorious soap-opera star, Crawford returned to the fray with another parody:

While Alan shows a movie I made in my old life, I have been busy helping my family. I have a little niece named Zivia who is back in northern Indiana... which is where my family comes from. Well, Zivia, wanted a web page but her mother, my younger sister Kumiko, is overwhelmed right now so I worked with Zivia and we put the page together. It is a true labor of love and you can see it along with more work at my own site. - Nikuko Konninger ${ }^{66}$

This time, however, Sondheim was out of patience. He promptly un-subscribed her from Cybermind:

I've taken her off this list. She wrote me asking if she could post the video ad to her group as an "example of Nikuko's past life”. I feel completely outraged by this, and won't tolerate it. I feel as if I'm being personally slammed and the work I (and others) have put into the video and texts is being violently mispresented and stolen... it's not... that I mind parodies or even my words taken - that's happened before. But I can't stand them being used for far right-wing purposes, over a period of weeks, as if the characters and concepts were her idea. - Alan, by the way this is the first time someone's been unsubbed from here... for over two years ${ }^{67}$.

Those who publicly responded to this message unanimously supported Sondheim's actions: "Thanks! I thought I was the only one who objected strongly to her way of being”68, “Ack, how awful! Good riddance”69; “I support Alan’s actions 100\%”70; “I think this is the right thing to do... Her persistence with it has become increasingly strange. I think she is luney”71. Crawford left Cybermind, but tempers remained frayed and the event still very much "alive”.

\footnotetext{
${ }^{65}$ Sondheim, “Millennium Screening in Three Days,” online posting, 23 February 2000, Cybermind B.

${ }^{66}$ Crawford, "For my Family,” online posting, 23 February 2000, Cybermind B.

${ }^{67}$ Sondheim, “Karen,” online posting, 24 February 2000, Cybermind B.

${ }^{68}$ Roxanne, “Re: Karen,” online posting, 24 February 2000, Cybermind B.

${ }^{69}$ Eloise, “Re: Karen,” online posting, 24 February 2000, Cybermind B.

${ }^{70}$ Gregory, “Re: Karen,” online posting, 24 February 2000, Cybermind B.

${ }^{71}$ Colin, “Re: Karen,” online posting, 24 February 2000, Cybermind B.
} 
During the period between these two parody events (covering the months from late January 2000 to late February 2000), discussions on Cybermind spilled over onto other email lists. When Crawford first published her website, Sondheim sent an email to a media arts discussion group called "Webartery":

Yesterday, Karen announced a website which was a takeoff of the material I've been working with, Konninger/Nikuko/parables, etc. It was nasty and ended up in pro-life diatribes, far right-wing stuff, which made me sick. Obviously on the Net I don't have ownership of my material (they've been appropriated before), but this frankly made me sick; I felt I was metaphorically robbed. (I got off Cybermind for a while.) It wasn't the prankster aspect which bothered me - it was the material reworked in the service of a politics which I align with Nazi control ${ }^{72}$.

Meanwhile, on another email discussion list called Netdynam (a mailing list to discuss

“Network Group Dynamics”), Crawford explained her motivation:

Alan treated Nikuko like dirt. He degraded her and I don't mean the sex but the way he described it without one ounce of romance or tenderness. That is what disgusted me. He never even described her face, her hair, her voice. Think of how one customarily describes a sweet and beautiful woman. I kicked the proverbial squirt bottle (the device used for disciplining unruly Petz) out of Alan's hands ${ }^{73}$.

Crawford's gestures can be read as, simultaneously, intimate and threatening. Sondheim's reactions suggest he felt flattered but also violated.

\section{Conclusion}

In terms of their conscious intentions, Sondheim and Crawford subscribe enthusiastically to what Ned Rossiter calls "the doctrine of fluid identities" that "characterises much theorisation of cyberculture" ${ }^{74}$. As we have seen, Sondheim is fond of speaking in his narratives, as one of his own avatars; while Crawford is fond of "writing in character" or using "multiple personae"75. Yet the rancour, hurt and anger that both participants claim to have felt during the parody events suggests that Sondheim's avatars and Crawford's personae are diverse expressions of a fairly fixed self. Ultimately, their creators treat them as their own possessions, extensions of a

\footnotetext{
72 Sondheim, “Prankster,” online posting, 29 January 2000, Webarty Discussion Group $<$ http://groups.yahoo.com/group/webartery/message/2487>.

${ }^{73}$ Crawford, “Avatars,” online posting, 29 February 2000, NetDynam.

74 Ned Rossiter, “Symposium Review, (dis)LOCATIONS: A Code in Search of a Process," RealTime (2002) 47 <http://www.realtimearts.net/rt47/rossiter.html>.

${ }^{75}$ Crawford, “Hiding in Plain Sight,” online posting, 11 June 2001, NetDynam.
} 
single personality. As one member of the Netdynam email list asked indignantly, “Nikuko's pages ring a change on exactly the identity-fluidity characteristic of Internet life that Alan explores in his creation of her. He can't really think he holds the copyright, can he?"76 It is true, of course, that on and off the net people assume a range of identities that can be reasonably inconsistent with each other. There is nothing hypocritical about Sondheim's distress at what he felt was a misappropriation of his characters. Nevertheless, the fact that the more Sondheim felt the stability of his avatars to be under threat, the more he asserted his own individual and unique set of "rights," suggests both the limits of the flexibility claimed for identity formation on the net and the extent to which net identities can be experienced (by their creators and those who respond to them) as present, tangible expressions of the unique, creative self of their author.

This provides resistance to those who argue for the liberationist power of electronically networked communication spaces through the deployment of a multiple and decentred subjectivity. However, my argument for challenging the narrative of the decentred subject differs slightly from those advanced by commentators such as Burkhalter, Hall or Sahay, surveyed above. In a sense, there is a "prior" problem that is not often addressed in the literature, namely, that the ideology of presence shapes online identity. Without a faith in the capacity for written communication to make present an author's emotions, creativity and political beliefs, identity - whether multiple or singular - could not be realised through email communication. Both Sondheim and Crawford behaved as if their avatars could be brought to life by written expression, by their authors' creative skill. Crawford, in particular, seemed to believe that her characters were members of a real family, capable of independent thought and deserving of certain rights (the "right to life,” for example). Indeed, as noted, a familial trope illustrates the manner in which Crawford imagines the struggles between her and Sondheim over the "lives" of their avatars. Sondheim's displeasure at his inability to control the appropriation of his avatars resulted in a high level of intimacy on Cybermind as members expressed their support for his plight. The interactions between Sondheim and Crawford demonstrate the crucial role played by presence in shaping the aesthetic and affective relations of mailing list culture.

\footnotetext{
${ }^{76}$ Geoffrey, “Re: Booted off of Cybermind,” online posting, 29 February 2000, NetDynam.
} 


\section{References}

Bassett, C. (1997) "Virtually Gendered: Life in an Online World”, in Ken Gelder and Sarah Thornton (eds) The Subcultures Reader pp.537-50, London, Routledge.

Baym, Nancy K. (1988) “The Emergence of On-Line Community”, in Steven Jones (ed.) CyberSociety 2.0: Revisiting Computer-Mediated Communication and Community, pp.35-68, Thousand Oaks, Sage.

Belsey, Catherine (2002) Critical practice. London: Routledge.

Benedikt Michael (ed). (1991) Cyberspace: First Steps. Cambridge, Mass: MIT Press.

Blood, Rebecca (2000) “Weblogs: A History and Perspective”, $<$ http://www.rebeccablood.net/essays/weblog_history.html>

Bruns, Axel and Joanne Jacobs (eds). (2006) Uses of Blogs. New York: Peter Lang.

Burkhalter, Byron (1999) "Reading Race Online: Discovering Racial Identities in Usenet Discussions”, in Marc A. Smith and Peter Kollock (eds) Communities in Cyberspace, pp.60-75, New York, Routledge.

Coyne, Richard (2001) Technoromanticism: Digital Narrative, Holism, and the Romance of the Real, Cambridge, Mass, MIT Press.

Danet, Brenda (1998) “Text as Mask: Gender, Play, and Performance on the Internet”, in Steve Jones (ed) CyberSociety 2.0: Revisiting Computer-Mediated Communication and Community pp.129-158, Thousand Oaks, Sage.

Derrida, Jacques (1976) Of Grammatology. Baltimore: Johns Hopkins University Press.

Dibbell, Julian (1996) “A Rape in Cyberspace: How an Evil Clown, a Haitian Trikster Spirit, Two Wizards, and a Cast of Dozens Turned a Database into a Society", in Mark Stefik (ed.) Internet Dreams: Archetypes, Myths, and Metaphors pp.293313, Cambridge, Mass, MIT Press.

Gelder Ken and Sarah Thornton (eds.) (1997) The Subcultures Reader, London, Routledge.

Glotz, Peter, Stefan Bertsch and Chris Locke (eds.) (2005) Thumb Culture: The Meaning of Mobile Phones for Society, Bielefeld, transcript Verlag.

Gratton, Johnnie (2000) Expressivism: The Vicissitudes of a Theory in the Writing of Proust and Barthes, Oxford, Legenda.

Gregg, Melissa (2006) "Posting with Passion: Blogs and the Politics of Gender", in Axel Bruns and Joanne Jacobs (eds) Uses of Blogs, pp.151-158, New York, Peter Lang.

Gumbrecht, Hans Ulrich (2004) Production of Presence: What Meaning Cannot Convey. Stanford: Stanford University Press.

Gumbrecht, Hans Ulrich and K. Ludwig Pfeiffer (eds.) (1994) Materialities of Communication, Stanford University Press.

Hall, Kira (1996) “Cyberfeminism”, in Susan C. Herring (ed.) Computer-Mediated Communication: Linguistic, Social and Cross-Cultural Perspectives, pp. 147-170, Amsterdam, Benjamins.

Harvey, David (2005) A brief history of neoliberalism, New York, Oxford University Press. 
Herring, Susan C. (2003) “Gender and power in on-line communication”, in J. Holmes and M. Meyerhoff (eds) The Handbook of Language and Gender pp.202-222, Oxford: Blackwell.

Herring Susan and Paolillo, John (forthcoming) "Gender and genre variation in weblogs", Journal of Sociolinguistics, 10(4), 2006; pre-publication version is available at <http://www.blogninja.com/jslx.pdf >

Hughes, Robert (1991) Shock of the New. London: Thames.

Jones, Steven (ed.) (1995) Cybersociety: Computer-Mediated Communication and Community, London: Sage.

Jones, Steven (ed.) (1998) CyberSociety 2.0: Revisiting Computer-Mediated Communication and Community, Thousand Oaks, Sage.

Kolko Beth and Reid, Elizabeth (1998) "Dissolution and Fragmentation: Problems in On-Line Communities”, in Steven Jones (ed) Revisiting Computer-Mediated Communication and Community pp.219-229, Thousand Oaks, Sage.

Kollock Peter and Smith Marc A. (eds.) (1999) Communities in Cyberspace. New York: Routledge.

Lievrouw Leah and Sonia Livingstone (eds). (2002) Handbook of New Media: Social Shaping and Consequences of ICTs. London: Sage.

Lovink, Geert (2002) Dark Fiber: Tracking Critical Internet Culture, Cambridge, Mass, MIT Press.

McRae, Shannon (1997) "Flesh Made Word: Sex, Text and the Virtual Body”, in David Porter (ed.) Internet Culture pp.73-86, New York, Routledge.

Miles, Adrian (2005) “Media Rich versus Rich Media” paper given at Blogtalk Downunder conference May 2005, Sydney: $<$ http://incsub.org/blogtalk/?page_id=76>

Milne, Esther (2004) “'Magic bits of paste-board': texting in the nineteenth century”, M/C - A Journal of Media and Culture, 6.6:

$<$ http://journal.media-culture.org.au/0401/02-milne.php>

Mitchell, William (1999) e-topia, Cambridge, Mass, MIT Press.

Munster, Anna (2006) Materializing New Media: Embodiment in Information Aesthetics, Hanover, Dartmouth College Press.

Porter, David (ed.) (1997) Internet Culture, New York, Routledge.

Poster, Mark (1990) The Mode of Information: Poststructuralism and Social Context. Cambridge, Polity.

Poster, Mark (1995) "Postmodern Virtualities", in Mike Featherstone and Roger Burrows (eds.) Cyberspace, Cyberbodies, Cyberpunk: Cultures of Technological Embodiment pp.379-382, London, Sage.

Reid, Elizabeth (1995) "Virtual Worlds: Culture and Imagination”, in Steven Jones (ed.) Cybersociety: Computer-Mediated Communication and Community pp.164-183, London, Sage.

Rheingold, Howard (1994) The Virtual Community: Surfing the Internet. London, Minerva. 
Rossiter, Ned (2007) "Symposium Review, (dis)LOCATIONS: A Code in Search of a Process.” RealTime 47 (2002),

<http://www.realtimearts.net/rt47/rossiter.html>

Sahay, Amrohini (1997) “'Cybermaterialism' and the Invention of the Cybercultural Everyday”, New Literary History 28(3): 543-67.

Sanbonmatsu, John (2003) The postmodern prince: critical theory, left strategy, and the making of a new political subject, NY, Monthly Review Press.

Sconce, Jeffrey (2002) Haunted Media: Electronic Presence from Telegraphy to Television, Durham, Duke University Press.

Senge, Peter, C Otto Scharmer, Joseph Jaworski, and Betty Sue Flowers (2005) Presence - Exploring Profound Change in People, Organisations and Society, London, Nicholas Brealey Publishing.

Sherry, Turkle (1995) Life on the Screen: Identity in the Age of the Internet, NY, Simon \& Schuster.

Slater, Don (2002) "Social Relationships and Identity Online and Offline”, in Leah Lievrouw and Sonia Livingstone (eds.) Handbook of New Media: Social Shaping and Consequences of ICTs pp.533-46, London, Sage.

Sobchack, Vivian (1994) "The Scene of the Screen: Envisioning Cinematic and Electronic 'Presence'”, in Hans Ulrich Gumbrecht and K. Ludwig Pfeiffer (eds) Materialities of Communication, pp.83-106, Stanford University Press.

Springer, Claudia (1996) Electronic Eros: Bodies and Desire in the Postindustrial Age, Austin, University of Texas Press.

Stefik, Mark (ed.) (1996). Internet Dreams: Archetypes, Myths, and Metaphors, Cambridge, Mass, MIT Press.

Stone Allucquére Rosanne (Sandy) (1991) "Will the Real Body Please Stand Up?: Boundary Stories about Virtual Cultures”, in Michael Benedikt (ed.) Cyberspace: First Steps pp.81-118, Cambridge, Mass, MIT Press.

Stone, Allucquére Rosanne (Sandy) (1995) The War of Desire and Technology at the Close of the Mechanical Age, Cambridge, Mass, MIT Press.

Wellman, Barry and Caroline Haythornthwaite (2002) The Internet In Everyday Life, Oxford, Blackwell. 